\title{
Deregulation redux: does mandating access to bottleneck facilities necessarily improve welfare?
}

\author{
Richard S. Higgins • Arijit Mukherjee
}

Received: 29 September 2009 / Accepted: 14 October 2009 / Published online: 28 October 2009

(C) Springer Science+Business Media, LLC 2009

\begin{abstract}
We demonstrate that deregulation in the form of vertical separation of network components into natural monopoly and potentially competitive markets does not truly represent a lessening of regulatory burdens. That is, vertical separation is not synonymous with deregulation; "more competitors" is not equivalent to "more competition". We assume a public interest regulator that is constrained to set a unit price that maximizes expected welfare subject to a break-even constraint. We show that under both symmetric and asymmetric information cases the information demands on the regulator of the vertically integrated system are no greater than those in the case of vertical separation.
\end{abstract}

Keywords Deregulation · Asymmetric information · Vertical integration

JEL Classification D82 $\cdot$ D86 $\cdot$ L43

\section{Introduction}

Economists have sought to explain government regulation of industry in numerous ways, each of which contrasts strongly with the so-called public-interest theory of regulation

Festschrift in Honor of Prof. Robert Tollison's $65^{\text {th }}$ Birthday.

Acknowledgements by RSH: Bob has contributed greatly over the course of his career to the foundation of an economic theory of government. Through the lens of empirical public choice he has advanced the theories of interest-group politics and rent-seeking and, by these efforts, he has expanded our understanding of the interaction of all branches of government right down to day-to-day regulation. Given the wealth of his work in these areas, I am honored to have been invited to write Bob's Festschrift to address issues in the economics of regulation. While I am confident that he will appreciate the problem we describe, I regret only that my methods are not in the spirit of his positivist empiricism.

R.S. Higgins

Bates White, LLC, Washington, DC, USA

e-mail: Richard.Higgins@bateswhite.com

A. Mukherjee ( $₫)$

Department of Economics, Michigan State University, East Lansing, MI, USA

e-mail: arijit@msu.edu 
(Stigler 1971; Jordan 1972; Posner 1974; Peltzman 1976, McCormick and Tollison 1980, 1981; Becker 1983; Maloney et al. 1984; McCormick et al. 1984; McChesney 1987, 1991, and Ekelund and Tollison 2001). While there are several contending economic theories of regulation, there is general agreement among them that the goals of any good theory of regulation include predicting when and where government intervention is likely to be used to regulate markets and identifying the instruments regulators are likely to apply (Crew and Rowley 1988 and Peltzman et al. 1989). Specifically, a good economic theory of regulation must explain the causes of deregulation, and at least two authors have attempted to do this (Keeler 1984 and Peltzman et al. 1989). In this paper, we demonstrate that in several important cases these authors have offered explanations for something nonexistent.

To be clear, we do not intend here to affirm any specific explanations for deregulation. Instead, we set ourselves a less ambitious goal of proving that much of such economic analysis has been misguided. To be precise, we contend and attempt to prove here that much of what has been and still is referred to as deregulation is really no such thing. Instead, this alleged deregulation is merely a reformulation of regulation. This error is not universal, however. The airline industry was by all reckoning deregulated-minimum fares and legal barriers to route entry were removed, and, so too was, the trucking industry, but, at the same time, we contend that there has been no significant deregulation in telecommunications, electric utilities and railroads, to name but three industries that most economists would cite as modern examples of deregulated industries.

Obviously, to the extent there is any cogency to this thesis, the conclusions of economists who have sought to evaluate the comparative explanatory power of the public-interest and the economic theory of regulation in telecommunications or electric utilities or railroads are irrelevant. These efforts provide explanations for something that "didn't happen". Our specific purpose is to prove, at least, that the case for deregulation has not been made and, perhaps more strongly, that there has been no deregulation in these industries.

We begin by providing a stylized description of telecommunications regulation before and after deregulation (see Ellig 2006). And, we really mean "stylized;" the Byzantine nature of telecom regulations then and now is beyond our comprehension. Although telecom is used as our illustration, an analogous situation exists in railroads and in electric utilities, which we will note at various points in our discussion of telecom regulation.

Prior to the break-up of AT\&T (1984), one company owned and operated virtually all of the local and long-distance telephone facilities in the United States. There was no Bell South connecting to Sprint's long-distance fiber network; instead, local telephone exchanges were owned by Ma Bell, which also owned the only access one had to local exchanges in the rest of the country or the world. Local telephone rates were regulated by state public utility commissions ("PUCs"), and long-distance rates-because in general there are prices for interstate calls-were set by the Federal Communications Commission ("FCC"). As you can guess, with 50 different regulators of local rates and one regulator of interstate rates with the goal of assuring that the entire enterprise was self-sufficient (including a "normal" return on capital), this was a regulatory nightmare - unless you were a regulator, of course. To make matters comprehensible we ignore here the complicating roles of the PUCs and assume that one grand regulator would set local and long-distance rates.

After the 1984 Modification of Final Judgment ("MFJ"), which final judgment refers to a court judgment against AT\&T from the early 1950s, the local exchanges were separated from the long lines division of AT\&T. The local exchanges or local loops were grouped into regions called "LATAs" and divested to investors. These initially comprised seven Regional Bell Operating Companies ("RBOCs") or Baby Bells. The long-lines division was left intact as the new AT\&T. The MFJ also prohibited the RBOCs from reentering the longdistance telecommunications business. Along with these "line of business" restrictions, the 
RBOCs were required to grant access on a nondiscriminatory basis to any long-distance carrier wishing to interconnect with the RBOCs' local exchanges.

The basis for this legal action was the prevailing view at the Justice Department's Antitrust Division that: (1) the local exchanges represent classic natural monopolies, while long-distance telecommunications are potentially competitive, and (2) vertically integrated bottlenecks (the RBOCs) would have incentives and the ability to foreclose nonaffiliated long-distance carriers in a variety of ways, which would raise the costs of these long-distance carriers and reduce competition in long-distance markets. Finally, the overarching implicit assumption was that confining government regulation, which most economists had finally come to admit has, at best, costs of its own, to the natural monopoly markets and allowing competition to "govern" price in nonnatural monopoly segments would enhance consumer or, perhaps, total welfare. Initially, the supposed gains from streamlined regulation were assumed, apparently, even to outweigh the economies of scope associated with vertical integration. ${ }^{1}$

Indeed, prior to the MFJ, firms were clamoring to enter the long-distance business to compete with the regulated monopolist, AT\&T. The story is complicated depending as it does on the role of radio transmission, which advanced substantially during WWII, and the PUCs' insistence on subsidizing local rates with too-high long-distance rates in the name of "universal service." We do not revisit these issues here, and, in particular, we do not address the efficacy of the Judge Greene's order to quarantine the RBOCs from the longdistance market. Instead, we focus on the immediate result, competing long-distance carriers separated from multiple local-exchange bottlenecks, and the extent to which this state of the world actually represents deregulation.

Specifically, we compare the burden of regulation in two scenarios: (1) regulation of the vertically integrated system of long-distance and local telecommunications, and (2) regulation of the same complementary markets post divestiture. That is, we compare regulation of vertical integration with regulation of vertical separation. In the first scenario, the regulator "chooses" local and long-distance rates, and, in the second scenario, the regulator chooses local rates and access charges. ${ }^{2}$ For the sake of this comparison, we assume public-interest government regulation with the same goals in the two scenarios. ${ }^{3}$ We evaluate the information demands of regulation in each scenario under two alternative presumptions about the completeness of information. In effect, the information demands of regulation in the two scenarios within the context of the neoclassical theory of natural monopoly and, alternatively, within the framework of the new economics of regulation are compared. For each context-complete and asymmetric information-we begin with a brief description of the welfare economics of natural monopoly regulation.

To motivate the discussion, telecommunications regulation is used to illustrate our thesis principally because we know most about this area. However, although we have not studied

\footnotetext{
${ }^{1}$ In fact, this was only the immediate effect. At present, some of the RBOCs have recombined into larger aggregations of local exchange bottlenecks and, in recognition of substantial economies of scope, mergers between RBOCs and long-distance carriers have been permitted.

${ }^{2}$ The hybrid case, prevalent in the United States today, in which the bottleneck is permitted to compete in the potentially competitive long-distance market is not analyzed here. This hybrid form of regulation requires that local rates and access charges be set as with vertical separation, and, in addition, the regulator must also be concerned with issues of vertical foreclosure. In some places in the world, especially Europe, the latter issues are overseen by the respective competition authorities not the rate regulators.

${ }^{3}$ Public-interest regulation is not assumed here because we think that it is better than the economic theory of regulation in explaining deregulation; instead, we do so because our thesis is largely independent of which theory is best and because the points made here are easier to make in this context.
} 
electric utility or railroad regulation as thoroughly, we think the same wishful thinking found among telecom regulators prevails there. For example, the electric transmission grid is a natural monopoly; it is used together with complementary inputs such as electric power generation, where lack of economies of scale does not preclude but, in fact, demands multiple generation plants. Applying regulation to the power grid while letting competition govern the price of power is considered by most economists to be an example of deregulation. But, just as in the case of telecommunications, as Al Phillips $(1982,1991)$ has cogently observed, competition is not synonymous with number of competitors.

Similarly, railroad-shipping tariffs are still determined ultimately through regulation when long-distance shippers have but one effective option. Specifically, shippers are allowed to contest rates whenever a fictitious railroad can be constructed-a virtual railroad - whose stand alone costs ("SAC") are consistent with Ramsey prices below those being offered by the railroad. In this way, the Surface Transportation Board intends to force the incumbent railroad to price as if it were being regulated by a public-interest regulator maximizing total welfare subject to a break-even constraint, notwithstanding its substantial sunk cost.

\section{Traditional welfare economics of natural monopoly}

\subsection{Brief theory review}

Natural monopoly is present when a single firm can satisfy market demand at a lower cost than can multiple suppliers. In the single-product case, the stylized model of natural monopoly assumes constant marginal cost and fixed, sunk cost. Thus, ex ante, average total cost declines and long- and short-run marginal cost is everywhere below long-run average cost. If the natural monopolist priced at marginal cost it could not be self-sufficient. ${ }^{4}$ If the natural monopolist were able to price unfettered by any government intervention typically it would price at the monopoly level and create deadweight loss. We say, "typically," because this result depends on additional assumptions about the nature of competition were there actual entry into the natural monopolist's market.

Natural monopoly may or may not be sustainable. Consider: with sunk cost, if Bertrand price competition were the appropriate model of competition in the counterfactual postentry world, there would be no entry, and, furthermore, there would be no credible threat of entry. As a result, the natural monopolist would enjoy the entire fruits of its monopoly under a laissez-faire policy without fear of entry eroding its profit. In contrast, if quantity-setting Cournot competition were the post-entry model of competition, entry might result. Specifically, the post-entry Cournot price might allow a margin sufficiently large to defray duplicative fixed, sunk costs of entry. In this event, the incumbent-assuming that the two so-called natural "monopolists" did not enter simultaneously-would have an interest, and the ability to compensate the entrant for not entering if this would postpone entry indefinitely. This follows directly from the fact that monopoly profit exceeds the sum of duopoly profits. However, since additional potential entrants would doubtless show up demanding compensation for not producing, one would predict actual entry under the supposed circumstances, absent interference from the government. ${ }^{5}$ While consumer welfare would be increased by entry of

\footnotetext{
${ }^{4}$ Natural monopoly is defined on the basis of declining long-run marginal cost over the range of demand; it is possible that short-run marginal cost rises under these circumstances.

${ }^{5}$ The federal Hatch-Waxman Act, among other things, protects branded drugs from competitive entry for a period beyond the first generic drug's appearance on the lip of the market. This creates value for contracts
} 
this sort, duopoly competition with duplicative investments in infrastructure would be likely to reduce total welfare. Thus, in a case like the one described, a laissez-faire regulatory policy would result in lower total welfare than would government regulation in the public interest.

First-best, public-interest regulation of natural monopoly requires in the first instance marginal cost pricing and, in the second instance, nondistortionary taxes or fixed fees to meet the inevitable revenue shortfall. The use of two-part tariffs by the regulator would seem a natural means of regulating natural monopoly, but is not common. ${ }^{6}$ We assume herein that the regulator is constrained perhaps for reasons related to income distributioni.e., political demands for universal service-to set price based on usage only. Thus, in the comparisons made herein we focus on second-best regulation. Specifically, in the example of telecommunications, we assume that message-unit prices are chosen by the regulator to maximize total welfare subject to a break-even constraint.

\subsection{Scenario 1: regulation of vertically integrated long-distance and local telecommunications}

In the simple case of a single-product natural monopoly, the regulator would force the regulated natural monopolist to satisfy demand at a price equal to its average long-run average cost-what is called TELRIC ("total expected long-run incremental cost") at the FCC. But, let us turn quickly to the two-product case of our illustrative model. Here, the definition of natural monopoly requires that for any pair of the two outputs-local and long-distance calls - the cost of producing the joint output is no larger than the cost of producing these outputs separately. This sub-additivity condition is trivially satisfied by the cost structure assumed here: local calls are produced at constant marginal cost, $C_{l}$, and long-distance calls require the services of the long-lines division and the local exchange, with full marginal cost, $C_{l d}+C_{l}{ }^{7}$ There is a fixed, sunk cost, $F$, associated with replicating the local exchange infrastructure. The demands for long-distance and local calls are independent. ${ }^{8}$ The demands are denoted, $Q_{l d}^{d}\left(P_{l d}\right)$ and $Q_{l}^{d}\left(P_{l}\right)$. Thus, the break-even constraint is

$$
Q_{l d}^{d}\left(P_{l d}\right)\left(P_{l d}-C_{l c}-C_{l}\right)+Q_{l}^{d}\left(P_{l}\right)\left(P_{l}-C_{l}\right)=F .
$$

In this simple case, the prices chosen by the public-interest regulator satisfy the familiar Ramsey pricing rule:

$$
\eta_{l} m_{l}=\eta_{l d} m_{l d} .
$$

In the equation above, the $\eta$ s represent the respective demand elasticities for local and longdistance service, and the $m$ s represent the Lerner indices (Ebrill and Slutsky 1990). The above condition states the familiar Ramsey pricing rule that percentage margins should be equi-proportional to the inverse of demand elasticities. ${ }^{9}$

\footnotetext{
not to compete between the incumbent and the first generic. Without such protection for initial generic entry, contracts of this sort would be worthless.

${ }^{6}$ If two-part tariffs were chosen, the subsidies required to sustain marginal-cost pricing would come from the consumers of the natural monopolist's product.

${ }^{7}$ Thus, most favorable to the case for deregulation, it is here assumed that long-distance telecommunications are provided at constant long- and short-run marginal cost.

${ }^{8}$ The independence assumption is not essential to the conclusions.

${ }^{9}$ When demands are interdependent, the relevant elasticities are called super-elasticities.
} 
Now, consider the information demands confronting the regulator in this context. With vertical integration, the regulator must know the two demands, the marginal costs and the fixed, sunk cost.

\subsection{Scenario 2: regulation of vertically separated long-distance and local telecommunications}

In this scenario, two prices for the local exchange bottleneck - the regulated firm-are set by the regulator: the final price for local calls, $P_{l}$, and the price of access, $A$, which governs the cost to the long-distance carriers of interconnecting with the local exchange bottleneck. ${ }^{10}$ Here, the price of long-distance calls is set through competition among the long-distance carriers whose marginal costs are uniform and equal to $C_{l d}+A$. In this vertical-separation scenario, the total surplus realized in the long-distance market depends on the nature and intensity of long-distance competition and the access price chosen by the regulator. Assuming that the regulator chooses $P_{l}$ and $A$ to maximize the sum of total welfare in the two markets subject to a break-even constraint for the local exchange monopoly, it is a simple task to demonstrate that the information demands on the regulator are at least as great as in the former vertical-integration scenario.

The break-even constraint in scenario 2 can be expressed as

$$
Q_{l d}^{d}\left(P_{l d}\right)\left(A-C_{l}\right)+Q_{l}^{d}\left(P_{l}\right)\left(P_{l}-C_{l}\right)=F .
$$

The regulator is assumed to maximize the sum of total welfare in the two markets subject to this breakeven constraint. The first-order conditions are:

$$
Q_{l d}^{d}\left(P_{l d}^{* *}\right)\left(A^{*}-C_{l}\right)+Q_{l}^{d}\left(P_{l}^{*}\right)\left(P_{l}^{*}-C_{l}\right)=F,
$$

and

$$
\eta_{l} m_{l}=\eta_{l d} m_{l d}
$$

where $P_{l d}^{* *}$ is a function of $A$ and $C_{l d}$ based on demand equals supply in the long-distance market, which equilibrium is anticipated by the regulator when it chooses the local rate and the access charge. ${ }^{11}$

With vertical separation, the information necessary for constrained maximization of total welfare actually exceeds that which is required in the former vertical-integration scenario. Specifically, in addition to the knowledge of the parameters required of the vertically integrated system regulator, the regulator in the vertical-separation scenario must also know the equilibrium concept applicable in the long-distance market. Of course, in the extreme, if perfect competition were a given, the regulator could infer $P_{l d}$ from knowledge of $A$ and $C_{l d}$ (since $P_{l d}=A+C_{l d}$ ), and his optimization problem with vertical separation would then entail no more information than with vertical integration. It is noteworthy also that when there are scale economies in the long-distance market and an oligopolistic market structure, the

\footnotetext{
${ }^{10}$ Implicitly, the regulated firm must satisfy all demand at the regulated price. Alternatively, the regulator could be envisioned setting output.

${ }^{11}$ There are multiple ways to specify the regulator's optimization problem in scenario 2 . The most natural posits a two-stage model in which the regulator anticipates the market equilibrium price relation in the longdistance market from stage 2 and chooses the values of $P_{l}$ and $A$ in stage 1 .
} 
regulator, even when armed with complete knowledge-including knowledge of the equilibrium concept - cannot achieve the second-best outcome as in the case of system regulation because of "double marginalization."

Apparently, the proponents of vertical separation —or, deregulation, as it is often calledthought, and may still think that competition in the potentially competitive segments would be so intense that near-perfect competition could be safely presumed. One could make quick work of this presumption in light of what has been observed in the long-distance segment: substantial sunk-cost investment and economies of scale. But, no matter; the important point here is that even if perfect competition were an appropriate presumption, the regulatory burden is no lighter with deregulation than without. This is because the regulator intent on maximizing total welfare in the two markets still must know long-distance demand and account for the effect of the access charge on price there. ${ }^{12}$

\section{The new economics of regulation}

We have shown that the regulator's problem requires as much or more information with vertical separation as with vertical integration and that, unless there is perfect competition, in potentially competitive markets, greater total welfare can be achieved with vertical integration than with vertical separation. In this context, the appellation "deregulation" clearly is misapplied, and economists who have attempted to explain such deregulation, at least in some industries, have been applying the economic theory of regulation to non-existent situations. In contrast, beginning in the 1980s and singularly punctuated by the publication of Laffont and Tirole's book in 1993 and the many articles written along similar lines, a new theory of regulation has been dominant in the economics literature. Based on the theory of incentive contracting, the so-called "New Economics of Regulation" focuses on the information asymmetry that presumably exists between the regulated firm and the regulator. ${ }^{13}$ In this section, we investigate the possibility that vertical separation reduces the information burden of regulation in the context of asymmetric information.

In this regard, we consider an even simpler version of the stylized model of telecommunications regulation described above, but with the additional element of asymmetric information. And we contrast the information requirements of full vertical integration with vertical separation of the local exchange natural monopoly and the potentially competitive long-distance sector.

\subsection{Review of basic theory}

The new economics of regulation is predicated on the presence of incomplete information, specifically "asymmetric information" (Laffont 1994). ${ }^{14}$ That is, whatever the goals of the regulator-here, we continue to assume public-interest regulation as described above- the regulated firm has private information about its own type-i.e., in simplest terms, whether it has high or low marginal cost—or its actions—e.g., its efforts to control costs that are

\footnotetext{
${ }^{12}$ Of course, if deregulation is accompanied by a more narrow welfare goal, such as total welfare in the local telecommunications market only, information demands would be lighter.

${ }^{13}$ As early as 1978 , together with John Hiller, Bob wrote an article questioning the uncritical acceptance among economists of the efficacy of incentive contracting (see Hiller and Tollison 1978).

${ }^{14}$ Uncertainty proper is not of much interest, provided the imperfect information is symmetric.
} 
relevant to the regulator's optimization problem. The first form of asymmetry, hidden information, is called "adverse selection," and the second, hidden actions, is called "moral hazard" (Arrow 1971).

A critical assumption of the new economics of regulation is that the regulator effectively contracts with the regulated firm in order to elicit the actual impacted information. Even if one were inclined to agree with the proffered institutional setup, such separating equilibrium contracts are not generally available. That is, in some instances, the best the hypothetical regulator can do is to maximize the expected value of its objective given the uncertain costs and the regulated firm's participation. As will be demonstrated, when incentive contracts are effective, the public interest regulator optimizes in such situations by leaving some but not all rents with the natural monopolist. Thus, the solutions are third-best compared to the results achievable with two-part pricing and complete information.

To demonstrate the regulator's choice more fully, we adopt the simplest model of asymmetric information: adverse selection, only, and no moral hazard. Specifically, for example, a single-product firm knows its marginal cost, but the regulator knows only that marginal cost falls within a range that supports a prior probability density function $(p d f)$, or, more simply, marginal cost is either low or high with probabilities $\alpha$ and $1-\alpha$. Ex post, cost is either not observable (or, alternatively, is observable but not verifiable) (see Baron and Myerson 1982) or is observable but contains a hidden effort component (Laffont and Tirole 1993). ${ }^{15}$ In such circumstances, the regulator is envisioned selecting a regulatory policy, which is defined in the present illustration as an assignment of price in response to a report from the firm about its marginal cost. Note: at one extreme, the regulatory policy might be "select the price that a profit-maximizing monopolist would charge if it had marginal cost, c." This is the laissez-faire regulatory policy-i.e., no regulation. At the other extreme, the regulatory policy would simply reimburse the firm for its reported average cost. In the first instance, the firm would report cost truthfully; in the second, the firm would lie and report an average cost equal to the monopoly price that corresponds to its true marginal cost. At both of these extremes, the firm would effectively go unregulated.

In general, with asymmetric information, the regulated firm has incentives to lie about its marginal cost. In this context, some regulatory policies are special because they elicit truth, telling by the regulated firm for all feasible values of its marginal cost. Such policies are called incentive-compatible regulatory policies. Further, a regulatory policy that relates the optimum value of the decision variable — here, price — directly to the measure of a firm's unknown type-here, marginal cost-is called a direct regulatory policy. According to the Revelation Principle, there is a direct, incentive-compatible regulatory policy, $P(c)$, that performs at least as well as any more complex, or indirect regulatory policy.

When the regulator must rely on voluntary participation by the regulated firm, there also is an additional constraint called the rational-participation constraint. Thus, ultimately, the problem for the hypothetical public-interest regulator is to find a direct, incentive-compatible regulatory policy, $P(c)$, that elicits active participation by the regulated firm and that maximizes expected total welfare. This is an optimal control problem: to choose the best function among a set of functions, where "best" here refers to maximum expected total welfare.

The optimal regulatory policy is a function denoted $P^{*}(c)$. It has the property of exceeding marginal cost when $c$ is at its minimum and equal to average cost when $c$ is at its maximum. Thus, the most efficient type of firm earns rents. And, the least-efficient type earns no rent whatsoever; it merely breaks even. Almost all of the time, the regulated firm

\footnotetext{
15 "Nonverifiable" here means that the cost observed ex post by the regulator cannot be substantiated or proven to a third party, such as an administrative court.
} 
earns "informational rents." The additional deadweight loss associated with prices above the break-even level is necessary to induce the firm to report its marginal cost truthfully.

\subsubsection{Digression on commitment}

In describing optimal regulatory policies it has been implicitly assumed that the regulator can commit to applying an incentive-compatible regulatory policy. Absent such commitment, the firm would expect the regulator to use the truthful information revealed about its marginal costs to force the firm to price as in the symmetric-information case, thus leaving no rent except that which is necessary to enable the firm to exactly cover all of its costs. Anticipating such ex post opportunistic conduct by the regulator, the firm would misreport its costs. There is only one ready means available to the regulator to make such a commitment. The regulator may solicit the aid of the courts, which could act as third-party enforcers of contracts to which, ex ante, both the regulator and the regulated would agree. ${ }^{16}$ Obviously, these contracts would have to be long-run contracts; otherwise, after one period of interaction with truth-telling, the regulator would know the firm's costs, and, in all subsequent rounds, the regulator-remember, the regulator is a public-interest regulator-would squeeze the rent out of the firm, which would deter the firm from reporting its costs accurately in the first instance.

Another problem arises, even with perfectly enforceable long-run contracts; in some instances, both parties to these contracts have incentives to renegotiate after some rounds of interaction. That is, the long-run contract alluded to immediately above would be breached with the mutual assent of each party - the regulator and the regulated firm. Unless the courts were willing to enforce contracts with penalties, which by assumption are contrary to the ex post mutual will of both parties, what was efficient ex ante would be undone ex post and thus would never happen to start with. ${ }^{17}$

Finally, of course, with or without a third-party enforcer, there are occasions when the regulator-even if there were such an entity (i.e., utility function) desirous of contracting in the manner described-is unable to strike the deals necessary to elicit truth-telling about private information. This possibility is discussed below.

\subsection{Vertical separation and vertical integration: comparing the information burdens of incentive regulation}

In this section, we apply the new economics of regulation to the simplest case that captures the potential differences in the information requirements of optimal regulation with and without vertical separation of complementary activities. The focus is on the long-distance market only; the local-exchange bottleneck facility is required to complete long-distance calls, but its use to complete local calls is ignored. Suppose that the firm is privately aware of its marginal cost, but the regulator does not know what the actual marginal cost is. All it knows is that the fixed cost is set at $F$, but the marginal costs for local-network access and long-distance service can either be low or high, with a certain prior probability distribution. It turns out that even in the presence of asymmetric information, vertical separation need not

\footnotetext{
${ }^{16}$ Bob has contributed to this literature as well. Together with Gary and Bill, Bob repaired an oversight in Landes and Posner (1975) by addressing judges' incentives to enforce the long-term agreements of legislatures and regulators (see Anderson et al. 1989).

${ }^{17}$ There has been research into the nature of so-called renegotiation-proof regulatory policies. We do not characterize the welfare properties of such regulatory solutions here, but see Chiappori et al. (1992).
} 
be more conducive to enhancing economic welfare. We illustrate this issue with the help of the following simple model.

With vertical separation, the local-exchange bottleneck is prohibited from competing in the long-distance market; it simply provides access to long-distance carriers. The marginal cost incurred by the local exchange is $c_{L}$, and the marginal cost of the long-distance provider is $c_{L D}$. There is a fixed long-run cost of sustaining the local network, $F$, and long-distance telecommunications entail no such fixed costs. The regulator does not know $c_{L}$ or $c_{L D}$, but knows the probability distributions from which these costs are drawn. However, the regulator possesses complete knowledge about long-distance demand and fixed cost $F$.

Alternatively, with vertical integration, the regulated monopolist combines long-distance and local-network services to provide a long-distance call. It is assumed that the longdistance carriers produce at a marginal cost, $c_{L D}$, which, for the sake of comparing the two regulatory regimes, is identical to the marginal cost for the long-distance carriers in the vertically separated market. As before, the regulator knows demand and $F$, but $c_{L D}$ is privately known by the long-distance carriers. Perfect competition is presumed among long-distance carriers. ${ }^{18}$

Alternative assumptions are made about the completeness of information about $c_{L}$ and $c_{L D}$ possessed by the regulator under vertical integration and, alternatively, vertical separation.

\subsubsection{Vertical separation}

Let us first consider the case of vertical separation. Consider a vertically separated telecommunication industry where a monopolist provides the local-exchange service, but there is perfect competition in the long-distance market. The monopolist faces a demand for the long-distance call that is represented by the demand curve $D(p)=1-p$. The cost structure of the monopolist is unknown to the regulator. All that the regulator knows is that the monopolist's total marginal cost can either be high at $\bar{c}_{L}$ with probability $\alpha$, or it can be low at $\underline{c}_{L}$ with probability $1-\alpha$. The social planner, as well as the local-exchange monopolist, is also unaware of the marginal cost of the long-distance providers. But it is known that the cost of the long-distance provider can either be high at $\bar{c}_{L D}$ with a known probability $\beta$ or low at $\underline{c}_{L D}$ with the remaining probability $1-\beta$. Let the expected cost at the long-distance level be $\widehat{c}_{L D}$. We further assume that the cost in the local exchange is statistically independent of the cost of the long-distance providers. The social planner's problem is to choose an access fee $A$ conditional on the reported cost (say $\underline{A}$ if the reported cost is $\underline{c}_{L}$, and $\bar{A}$ if the reported cost is $\bar{c}_{L}$ ) that ensures participation, or individual rationality $(I R)$, and incentive compatibility $(I C)$, and maximizes social welfare. Using the above functional form for $D(p)$, the social planner's problem can be written as:

$$
\begin{aligned}
& \max _{\{\underline{A}, \bar{A}\}} \quad \alpha E_{c_{L D}} {\left[\frac{1}{2}\left(1-c_{L D}-\bar{A}\right)^{2}+\left(\bar{A}-\bar{c}_{L}\right)\left(1-c_{L D}-\bar{A}\right)\right] } \\
&+(1-\alpha)\left[\frac{1}{2}\left(1-c_{L D}-\underline{A}\right)^{2}+\left(\underline{A}-\underline{c}_{L}\right)\left(1-c_{L D}-\underline{A}\right)\right]
\end{aligned}
$$

\footnotetext{
${ }^{18}$ We demonstrated in the section with complete information that the regulator under vertical separation is at a fundamental disadvantage when the competitive market structure of the long-distance market is less-thanperfectly competitive. Thus, with respect to the advantage of the vertical-separation outcomes over those with system regulation, perfect competition is assumed to prevail in the long-distance market.
} 
Fig. 1 A possible solution to the regulator's problem

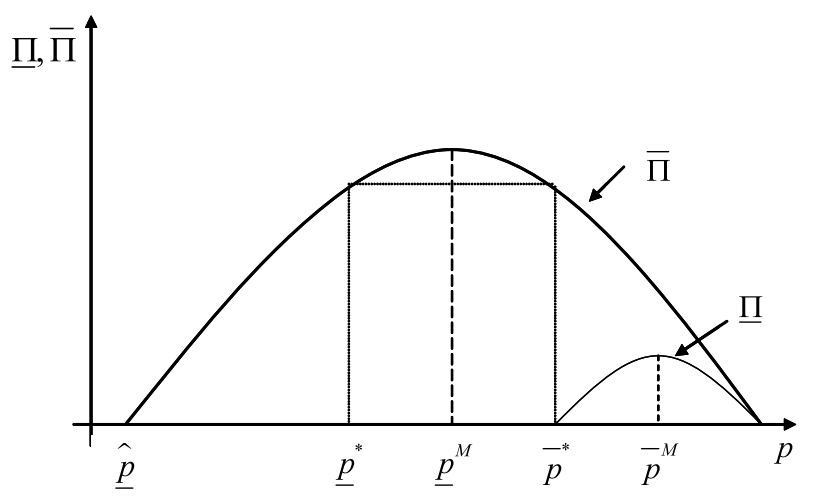

subject to

$$
\begin{aligned}
& \left(\bar{A}-\bar{c}_{L}\right)\left(1-\hat{c}_{L D}-\bar{A}\right) \geq\left(\underline{A}-\bar{c}_{L}\right)\left(1-\hat{c}_{L D}-\underline{A}\right) \quad(\overline{I C}) \\
& \left(\underline{A}-\underline{c}_{L}\right)\left(1-\hat{c}_{L D}-\underline{A}\right) \geq\left(\bar{A}-\underline{c}_{L}\right)\left(1-\hat{c}_{L D}-\bar{A}\right) \quad(\underline{I C}) \\
& \left(\bar{A}-\bar{c}_{L}\right)\left(1-\hat{c}_{L D}-\bar{A}\right) \geq F \quad(\overline{I R}) \\
& \left(\underline{A}-\underline{c}_{L}\right)\left(1-\hat{c}_{L D}-\underline{A}\right) \geq F \quad(\underline{I R}) .
\end{aligned}
$$

Observe that this problem is intrinsically different from the textbook case of a menu contract with two types of agent. Thus, unless some special parametric restrictions are considered, there may not exist a contract that induces truthful revelation of the underlying cost. A typical case where there indeed exists a solution to the regulator's problem is depicted in Fig. 1.

Figure 1 depicts the expected profits net of fixed cost $F$ ( $\bar{\Pi}$ and $\underline{\Pi}$ respectively) of a high- and low-type local exchange provider as a function of the market price, where the expectation is taken over the marginal cost of the long-distance provider. If the monopolist goes unregulated, a high-cost monopolist will charge a monopoly price $\bar{p}^{M}$, and a low-cost monopolist will charge a monopoly price $p^{M}$. If the regulator has perfect knowledge of the monopolist's underlying cost, the regulator will set a price as close to the marginal cost as possible subject to the fact that the monopolist can still recoup its fixed cost by selling the product at the regulated price. ${ }^{19}$ In terms of the notation given in Fig. 1, the regulator would set a price $\bar{p}^{*}$ if the cost is high and a price $\widehat{p}$ if the cost is low.

However, $\left\{\widehat{p}, \bar{p}^{*}\right\}$ cannot be a solution to the regulator's problem if the marginal cost of production is only privately known to the monopolist. This is due to the fact that in this case, the low-cost monopolist has an incentive to misreport his cost and take advantage of the high price $\left(\bar{p}^{*}\right)$ by pretending to be a high-cost firm. In other words, the $(\underline{I C})$ constraint is violated. Now suppose that monopolist is more likely to be the high-cost type. ${ }^{20}$ Thus, the regulator may find it optimal to set the price for high-cost type as low as possible (subject to the participation constraint), and choose the price for the low-cost monopolist as low

\footnotetext{
${ }^{19}$ Observe that the social surplus monotonically increases with prices until the price becomes equal to the marginal cost.

${ }^{20}$ Unless participation is mandatory, regardless of the firm's type, the regulator might choose to ignore the high-cost firm altogether if the probability of low cost is sufficiently high. In this case, the regulator would set the price at the low marginal cost and take its chances that the firm is a low-cost type firm, since under this contract the high-cost firm would stay out.
} 
as possible provided it has no incentive to misreport its cost. This is achieved when the regulator sets a price, say $\underline{p}^{*}$ (as shown in Fig. 1), for the low-cost monopolist such that the profit of the low-cost monopolist at $p^{*}$ is exactly equal to the profit it will earn if it attempts to misreport its cost as a high-cost firm. In other words, the regulator may find it optimal to choose prices such that the high type just breaks even, and the low type's incentive compatibility binds.

It is however important to note that for such a contract to be feasible, it is essential that $p^{M}<p^{*}$; this has been implicitly assumed in Fig. 1. Observe that in this solution both $p^{*}$ and $\bar{p}^{*}$ are above the corresponding marginal costs. There are two sources of inefficiency in this setting. First, the regulator must set the price above the marginal cost in order to allow the monopolist to recoup its fixed cost. For this reason, $\bar{p}^{*}$ remains higher than $\bar{c}$. Second, the regulator must leave an "information rent" with the low-cost monopolist in order to induce truth-telling. This inflates the low-cost monopolist's price $p^{*}$ even more above its marginal cost $\underline{c}$.

\subsubsection{Vertical integration}

Does vertical separation necessarily outperform vertical integration? Using the simple example discussed above, we would argue that vertical integration might actually allow the regulator to offer a more efficient contract that may improve the social welfare. To see this, let us reconsider the model discussed in the case of vertical separation with one major modification: assume that instead of perfect competition in the long-distance provider market, the local exchange monopolist serves both the local exchange and the long-distance market. As before, we will assume that the cost of production is $c_{L}$ at the local exchange level and $c_{L D}$ at the long distance level, and the total cost of production is $c_{L}+c_{L D}$. Thus, with vertical integration, the monopolist can have four cost types:

$$
\begin{array}{ll}
\underline{c}_{L}+\underline{c}_{L D} & \text { with probability }(1-\alpha)(1-\beta) \\
\bar{c}_{L}+\underline{c}_{L D} & \text { with probability } \alpha(1-\beta) \\
\underline{c}_{L}+\bar{c}_{L D} & \text { with probability }(1-\alpha) \beta \\
\bar{c}_{L}+\bar{c}_{L D} & \text { with probability } \alpha \beta .
\end{array}
$$

The social planner's problem is to choose an incentive-compatible, individually rational contract that offers a price $P$ based on the reported marginal cost of the monopolist. Whether the social welfare under vertical integration is greater or smaller than the social welfare under vertical separation may depend on the underlying parameters of the model. However, the example presented here indicates one important reason why vertical integration may dominate vertical separation: under vertical integration, the regulator can manipulate the price charged by the monopolist not only for each realization of the upstream cost $\left(c_{L}\right)$ but also for each realization of the downstream $\operatorname{cost}\left(c_{L D}\right)$. In contrast, under vertical separation, the regulator cannot "fine tune" the contract to screen across the various cost realizations in the downstream long-distance market. In other words, vertical integration may allow the regulator to contract on a more informative set of signals (regarding the true underlying cost). Of course, the regulator may find it necessary to leave larger information rents to the monopolist in order to screen each realization of the upstream as well as downstream cost. It is important to recognize, however, that the efficiency gains from the possibility of screening each upstream and downstream cost realization may outweigh any such cost. ${ }^{21}$

\footnotetext{
${ }^{21}$ A simple way to see this logic is to consider the case of two cost types, as is the case with the vertical separation. Suppose, for some exogenous reason, the regulator must announce a single access price at which
} 
Thus, even under the conditions most favorable to vertical separation-perfect longdistance competition - the social welfare associated with regulating only the bottleneck monopoly may not exceed that achievable with regulation of the vertically integrated system. Moreover the information demands are no lighter with vertical separation. ${ }^{22}$

\section{Conclusion}

By the 1970s, economists on both sides of the aisle were distancing themselves from the uncritical supporters of government regulation (see Stigler and Friedland 1962 and Averch and Johnson 1962). But, to our knowledge no contemporaneous explanation was provided by the economists in support of the much-vaunted deregulation of the 1970s and 1980s, defined as "vertical separation." There are the obvious superficial reasons, which may have gone by without saying as would be appropriate for things obvious: "government regulation is intrusive and lends itself to industry capture so let's minimize its reach and, surely, by eliminating regulation in potentially competitive markets the overall burden of regulation will be lessened." Or, perhaps more cogently, "regulators need information to regulate in the public interest; if we reduce regulatory information demands by removing regulation in the potentially competitive segments, the burden of regulation will be lightened."

First, justification for vertical separation depends critically on the nature of the information that is present. It is unassailable that the more information available to the regulator about the costs of the specific lines of business it is charged with regulating the better the regulator's control over the regulated firm is likely to be. It is problematical, however, whether separating natural-monopoly segments from so-called potentially competitive, complementary segments lightens the regulator's information burden or merely shifts its locus. Certainly, information about the mechanisms governing price determination for long-distance

the upstream monopolist must give access of the local exchange to the long-distance providers. Now, for example, if the probability that the monopolist is of high-cost type is not too large, the regulator may set an access price equal to $\widehat{p}$, at which the low-cost type breaks even but the high-cost type shuts down (see Fig. 1). Now suppose that the regulator is indeed allowed to screen the two cost types, and the resulting optimal contract specifies the access prices $\left\{p^{*}, \bar{p}^{*}\right\}$, as is the case discussed under the vertical separation section. Now, in the latter case, the regulator must leave additional information rent with the low-cost firm, but in return it can ensure that both the high- and low-cost type firm participates. For suitable values of $\alpha$ (the probability of a high-cost realization), this enhanced participation may increase efficiency more than the loss of surplus as a result of the additional information rent that the low-cost type must earn under a screening contract.

${ }^{22}$ There is a small but growing literature that attempts to highlight various economic effects that may favor vertical separation over vertical integration. De Fraja (1999) considers an environment where an upstream monopolist owns an essential input. The regulator decides whether to leave the monopolist unregulated where it will supply the downstream final goods market as well or whether to regulate the monopolist and allow entrants in the downstream market who may access the essential input from the monopolist at a regulated access price. De Fraja argues it may be optimal to encourage entry even if the entrant is less efficient than the monopolist, provided that the entrant is not "too inefficient." The basic idea is that under vertical integration, the regulator cannot observe the "subcosts." It cannot tell whether the total cost (which the regulator observes) has originated from the essential input that the regulated firm has a monopoly on or whether it has originated from other inputs of production. This fact allows the monopolist to extract additional information rent. By allowing entry, the regulator can mitigate the needs for such information rent and increase social welfare. More recently, Gautier and Mitra (2005) offer a different argument for encouraging vertical separation: in addition to enhancing competition in the downstream market, it may facilitate the financing of the essential input. The authors argue that when the cost of the upstream monopolist is unknown, the regulator must leave socially costly information rent with the monopolist. The regulator can reduce the need for information rent by substituting the monopolist's production with the entrant's production. 
telecommunications or electric power generation or railroad tariffs is not free. Without such information, optimal regulation of natural monopoly with a complementary market or markets whose prices are governed by oligopolistic competition may be as elusive as optimal regulation of the corresponding vertically integrated system.

Second, we are not aware of any contemporaneous economic analysis in support of the contention that more competitors means more competition in three of the most cited examples of network deregulation: telecommunications, electric power generation and distribution, and railroad transportation. That is, neither at the time these industries were "deregulated" nor since have economists demonstrated the advantages of the new regulatory framework over the system-wide regulation of the past (but, see Noam 1992 and Kwoka 2006).

In this paper, we compare public-interest regulation of a vertically integrated system with similar regulation of a vertically separated system under two assumptions about information: symmetric and asymmetric information. We find that unless the potentially competitive markets open to entry under vertical separation are perfectly competitive the regulator will be hamstrung in its efforts by the mere fact of double marginalization. For this reason alone, the regulator will be unable to achieve with vertical separation the same level of welfare that results in the vertical integration case, even with complete information. We also find that under conditions of perfect competition in the "potentially competitive" markets and ignoring any synergies associated with vertical integration, vertical separation is unlikely to dominate vertical integration. This is because with vertical integration and incentive contracting to address asymmetric information, if expected welfare is larger when the regulator and the natural monopolist do not contract on marginal cost in the potentially competitive market, the optimal contract will reflect this. That is, the regulator can do no worse with the possibility of contracting on all cost dimensions than on a restricted number of them.

\section{References}

Anderson, G., Shughart, W., \& Tollison, R. D. (1989). On the incentive of judges to enforce legislative wealth transfers. Journal of Law and Economics, 32, 215-228.

Arrow, K. J. (1971). Essays in the theory of risk bearing. Chicago: Markham.

Averch, H., \& Johnson, L. L. (1962). Behavior of the firm under regulatory constraint. American Economic Review, 52, 1052-1069.

Baron, D. P., \& Myerson, R. B. (1982). Regulating a monopolist with unknown costs. Econometrica, 50, 911-930.

Becker, G. S. (1983). A theory of competition among pressure groups for political influence. Quarterly Journal of Economics, 98, 371-400.

Chiappori, P. A., Macho, I., Rey, P., \& Salanie, B. (1992). Repeated moral hazard: The role of memory, commitment and the access to credit markets. Mimeo.

Crew, M. A., \& Rowley, C. K. (1988). Towards a public choice theory of monopoly regulation. Public Choice, 57, 49-67.

De Fraja, G. (1999). Regulation and access pricing with asymmetric information. European Economic Review, 43, 109-134.

Ebrill, L. P., \& Slutsky, S. M. (1990). Production efficiency and optimal pricing in intermediate-good regulated industries. International Journal of Industrial Organization, 8, 417-442.

Ekelund, R., \& Tollison, R. D. (2001). The interest group theory of government. In W. F. Shughart \& L. Razzolini (Eds.), The Elgar companion to public choice (pp. 357-378). London: Edward Elgar.

Ellig, J. (2006). Costs and consequences of Federal Telecommunications Regulations. Federal Communications Law Journal, 58, 38-95.

Gautier, A., \& Mitra, M. (2005). Regulation of an open access essential facility. Mimeo.

Hiller, J., \& Tollison, R. D. (1978). Incentive versus cost-plus contracts in the defense industry. Journal of Industrial Economics, 26, 239-248.

Jordan, W. A. (1972). Producer protection, prior market structure and the effects of government regulation. Journal of Law \& Economics, 15, 151-176. 
Keeler, T. W. (1984). Theories of regulation and the deregulation movement. Public Choice, 44, $103-145$.

Kwoka, J. E. (2006). The role of competition in natural monopoly: Costs, public ownership, and regulation. Review of Industrial Organization, 29, 127-147.

Laffont, J.-J., \& Tirole, J. (1993). A theory of incentives in procurement and regulation. Cambridge: MIT.

Laffont, J.-J. (1994). The new economics of regulation ten years after. Econometrica, 62, 507-537.

Landes, W. M., \& Posner, R. A. (1975). The independent judiciary in an interest- group perspective. Journal of Law \& Economics, 18, 875-901.

Maloney, M., McCormick, R., \& Tollison, R. D. (1984). Economic regulation, competitive governments, and specialized resources. Journal of Law and Economics, 27, 329-338.

McChesney, F. S. (1987). Rent extraction and rent creation in the economic theory of regulation. Journal of Legal Studies, 16, 101-118.

McChesney, F. S. (1991). Rent extraction and interest-group organization in a Coasean model of regulation. Journal of Legal Studies, 20, 73-90.

McCormick, R., Shughart, W., \& Tollison, R. D. (1984). The disinterest in deregulation. American Economic Review, 74, 1075-1079.

McCormick, R., \& Tollison, R. D. (1980). Wealth transfers in a representative democracy: Theory and evidence. In Buchanan, Tollison, \& Tullock (Eds.), Toward a theory of rent-seeking society. Texas: A\&M.

McCormick, R., \& Tollison, R. D. (1981). Politicians, legislation and the economy: an inquiry into the interest-group theory of government. Boston: Nijhoff.

Noam, E. M. (1992). Assessing the impacts of divestiture and deregulation in telecommunications. In Symposium: divestiture and deregulation in telecommunications (pp. 438-449).

Peltzman, S. (1976). Toward a more general theory of regulation. Journal of Law \& Economics, 19, 211-240.

Peltzman, S., Levine, M. E., \& Noll, R. G. (1989). An economic theory of regulation after a decade of deregulation. Brookings Papers on Economic Activity: Microeconomics, 1989, 1-59.

Phillips, A. (1982). The impossibility of competition in telecommunications: Public policy gone awry. In M. Crew (Ed.), Regulatory reform and public utilities (pp. 7-33). Lexington: Lexington Books.

Phillips, A. (1991). Changing markets and institutional inertia. Telecommunications Policy, February, 49-61.

Posner, R. A. (1974). Theories of economic regulation. Bell Journal of Economics, 5, 335-358.

Stigler, G., \& Friedland, C. (1962). What can regulators regulate? The case of electricity. Journal of Law \& Economics, 5, 1-16.

Stigler, G. (1971). The theory of economic regulation. Bell Journal of Economics \& Management Science, 2, $3-21$. 